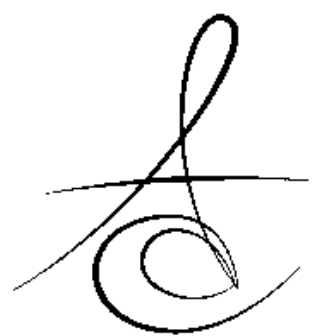

Makale Kodu/Article code: 1538

Makale Gönderilme tarihi: 19.02.2014

Kabul Tarihi: 12.03 .2014

\section{SERAMİK ABUTMENTLERİN MEKANİK, BİYOLOJİK VE ESTETİK AÇIDAN DEĞERLENDİRİLMESİ}

\section{EVALUATION OF CERAMIC ABUTMENTS IN MECHANICAL, BIOLOGICAL AND ESTHETICAL PERSPECTIVE}

Arş. Gör. Dt. Burcu GÜNAL*

Prof.Dr. M. Mutahhar ULUSOY*

Arş. Gör. Dt. Turhan Melih DURMAYÜKSEL*

Yrd. Doc. Dr. Sevcan KURTULMUS-YILMAZ*

\section{ÖZET}

Günümüze kadar titanyum, implant tedavilerinde abutment materyali olarak hakim bir yer almaktaydı. Ancak, yüksek estetik restorasyon beklentileri seramik abutmentlerin gelişmesini sağlamıştır. Günümüzde, zirkonya ve alumina abutmentler estetik bölgelerde yaygın olarak kullanılmaktadır. Estetiğin dışında, implant çevresi yumuşak doku sağlığı ve mekaniksel dayanıklılık da abutment materyali seçiminde önemlidir. Bu makalenin amacı seramik abutment materyallerini; mekanik, biyolojik ve estetik özelliklerini in vivo ve in vitro açıdan inceleyen literatürlerin değerlendirilmesidir.

Anahtar Kelimeler: Seramik abutment, zirkonya, alumina, mekanik direnç, bakteri adezyonu, plak akümülasyonu, estetik.

\section{GİRIş}

İmplant destekli tedavilerin klinisyen ve hasta tarafından başarılı olarak tanımlanabilmesi için, implantın iyi osteointegre olmasının yanı sıra kullanılan abutment materyalinin mekanik, biyolojik ve estetik açıdan bazı gereksinimleri karşılayabilmesi gerekmektedir. $^{1,2}$

Titanyum, mükemmel materyal stabilitesi, distorsiyona direnci ve uzun dönem klinik çalışmalardaki başarısı ile yakın zamana kadar, implant destekli protezlerin klinik ömürleri açısından abutment materyalleri içinde altın standart olarak kabul edilmekteydi. ${ }^{3,4}$ Ancak, günümüzde estetiğin ön plana çıkması ile birlikte titanyum abutmentler, implant çevresi mukozada oluşturduğu yansıyan gri renkleriyle, özellikle

\section{ABSTRACT}

To date, Titanium has hold a dominant position as an abutment material in implant therapy. However, the demands for highly esthetic restorations led to the development of ceramic abutments. Currently, zirconia and alumina abutments are widely used in esthetic regions. Besides esthetics, peri-implant tissue health and mechanical strenght are also important in the selection of abutment material. The purpose of this article is evaluation of the in vivo and in vitro studies of the mechanical, biological and esthetic properties of abutment materials.

Keywords: Ceramics abutments, zirconia, alumina, mechanical strenght, bacterial adhesion, plaque accumulation, esthetics.

dişetlerinin ince olduğu ve implantın bukkale doğru yerleştirildiği vakalarda yetersiz kalmaktadırlar., 5aha estetik bir materyal arayışı sonucu, seramik abutmentler tercih edilen materyaller arasına girmiştir. ${ }^{7}$

Seramik abutment ilk kez 1993 yılında üretilmiş ve estetik açıdan implant teknolojisinde önemli bir dönüm noktası olmuştur. ${ }^{7,8}$ Geliştirilen ilk seramik abutmentler, metal destekli seramik kronların makaslama kuvveti direncine ulaşan alümina seramik protipidir.9,10 Metal abutmentlerle karşılaştırıldığında; düşük korozyon, yüksek biyouyumluluk ve düşük termal iletkenlik gibi özelliklere sahiptir. Diğer taraftan, metal destekli seramik restorasyonlar ile karşılaştırıldığında, seramik korlarla yapılmış restorasyonlar daha dayanıksızdır. ${ }^{11}$ Bu nedenler, seramik abutmentler için yeni dizayn ve materyal arayışına yol açmıştır ve alumina bloklar (In Ceram, Vita, Bad Säckingen, Almanya) kullanılarak kişisel seramik abutmentler

*Yakın Doğu Üniversitesi Diş Hekimliği Fakültesi Protetik Diş Tedavisi, 
üretilmiştir.9,12 İyi bir estetik sonuç için diğer bir yenilik, uyumlanabilir CerAdapt (Nobel Biocare, Goteborg, İsveç) abutmentlerin gelişimidir. Bu abutment, yüksek sinterli aluminyum oksitten oluşmaktadır ve önceki abutmentlere göre daha dayanıklıdır. Saf aluminyum oksit partikülleri, seramiklere katılarak $1800^{\circ} \mathrm{C}$ gibi çok yüksek Isılarda sinterize edilmek- tedir. ${ }^{12,13}$

Titanyum abutmentler ile kıyaslandıklarında alumina abutmentler, diş benzeri renkleri ile estetik açıdan tatmin edici bulunmuşlardır ancak, mekanik dirençleri daha düşüktür ve kırılma riskleri daha yüksektir. ${ }^{4,6}$ Alumina abutmenler, radyografik incelemedeki radyoopaklığı ve düşük kırılma dayanıklılıkları nedeniyle günümüzde fazla kullanım alanları yoktur. ${ }^{11}$ Sadece ön bölge diş eksikliklerinde tek implant üzerinde kullanılan alüminyum oksit abutmentler ortalama $280 \mathrm{~N}^{\prime}$ luk kırılma dayanıklılıkları nedeniyle posterior bölgede kullanılması önerilmemektedir. ${ }^{10,14}$

Son zamanlarda seramik abutment materyali olarak, zirkonyum oksitler kullanılmaktadır. ${ }^{15}$ Glauser ve ark. ${ }^{16}$ yoğun sinterlenmiş itriyum ile stabilize zirkonları, alternatif seramik abutment olarak tanımlamışlardır. Seramiklerin içerisinde, yüksek oranda $\mathrm{ZrO}_{2}$ (zirkonyum oksit) partikülleri bulunmaktadır. Sinterizasyon sonucunda, oda sıcaklığında kısmen stabil olan tetragonal bir yapı oluştururlar. Oda sıcaklığında oluşan stabil yapının korunabilmesi amacıyla $\mathrm{ZrO}_{2}$ içerisine, kısmen veya tam stabilizasyon sağlayan $\mathrm{Y}_{2} \mathrm{O}_{3}$ (itriyum oksit), $\mathrm{MgO}$ (magnezyum oksit), $\mathrm{CaO}$ (kalsiyum oksit) ve $\mathrm{CeO}_{2}$ (seryum oksit) gibi farklı oksitler katılmaktadır. ${ }^{2,12}$

Zirkonyum oksit ve alüminyum oksit abutmentlerin birbirlerine göre farklı avantaj ve dezavantajları bulunmaktadır. Zirkonyum oksitin radyoopasitesi alüminyum oksitten daha fazla olduğundan, zirkonyum oksit abutmentlerin radyolojik tetkiki daha kolaydır. Zirkonyum oksitin açık beyaz renginden dolayı dişetinin kapatmadığı bölgelerde veya ince mukozalarda görünme riski varken, buna karşın alüminyum oksidin renk uyumu daha iyidir. ${ }^{1,17}$ Zirkonyum oksit abutmentler, alüminyum oksit abutmentlere göre daha iyi mekanik özelliklere sahiptir. Yüksek çiğneme streslerine karşı daha dayanıklıdırlar. Aluminyum oksit abutmentler, stresler karşısında mikro çatlaklar oluşurduğu için, preparasyon veya yerleştirme sırasında abutment kırımaları daha fazla karşılaşılmaktadır. Zirkonyum oksitin işlenmesi zor olduğu için, preparasyonu zor ve uzun sürmektedir. ${ }^{17,18}$
Günümüze kadar çeşitli firmalar farklı yapıda ve şekilde seramik abutment üretmiştir. İlk olarak 1993 yılında Nobel Biocare (Goteborg, İsveç) Firması CerAdapt adında simante saf alüminyum oksit abutmenti üretmiştir. ${ }^{7}$ Daha sonraları Friadent (Mannheim, Almanya) firması metal bir platform ile implanta vidalanabilen ve bu titanyum platforma adeziv siman ile yapıştırılan prepare edilebilen CeraBase alüminyum oksit abutmenti geliştirmiştir. Günümüzde ITI (Basel, İsviçre), Zimmer (İndiana, Amerika), Friadent (Mannheim, Almanya), Biohorizons (Alabama, Amerika), Procera (Goteborg, İsveç), Biolok (Alabama, Amerika) gibi implant firmalarının zirkonyum oksit abutmentleri mevcuttur. Zirkonyum oksit abutmentler metal platformlu veya monoblok yapıda üretilmektedir. Monoblok zirkonyum oksit abutmentlerde metal bir alt yapı mevcut değildir. ${ }^{14}$

\section{SERAMİK ABUTMENTLERİN MEKANİK YÖNDEN DEĞERLENDİRİLMESİ}

Seramik abutmentlerde tercih edilen materyaller, yüksek oranda sinterlenmiş yüksek saflıkta alumina $\left(\mathrm{Al}_{2} \mathrm{O}_{3}\right)$ ve itriyum ile $\left(\mathrm{Y}_{2} \mathrm{O}_{3}\right)$ stabilize edilmiş tetragonal zirkonya polikristal seramikleridir. ${ }^{19}$ Alumina seramiklerin $400 \mathrm{MPa}$ bükülme dayanıklılıkları, 5-6 $\mathrm{MPa} / \mathrm{m}^{0,5}$ kırılma sertlikleri ve $350 \mathrm{GPa}$ elastik modülleri vardır. İtriyum ile stabilize edilmiş zirkonya seramikler (Y-TZP), alumina seramiklerin bükülme dayanıklılı̆ının iki katına (900-1400 MPa) sahiptir, kırılma dayanıklılıkları $10 \mathrm{MPa} / \mathrm{m}$ ve elastik modülleri 210 GPa'dır. ${ }^{20,21}$ Alumina ile karşılaştırıldığında zirkonyanın yüksek dayanıklılığı; daha yüksek yoğunluk, küçük partikül boyutu ve çatlak oluşumuna karşı polimorfik mekanizması ile açıklanabilir. Zirkonyanın daha yüksek kırılma dayanıklıı̆ı, oda sıcaklığında $\left(18-23^{\circ} \mathrm{C}\right)$ tetragonal yapıda olmasını sağlayan itriyuma bağlanabilir. Oda sıcaklığındaki tetragonal faz, stres altında monoklinik faza geçişi sağlayarak çatlak ilerlemesini engeller. Hacimsel genleşme sonucunda, baskı kuvvetleri oluşur ve çatlak ilerlemesi engellenir ve mekanik özellikler artar. ${ }^{9,10,17}$

Sundh ve Sjögren ${ }^{22}$ in vitro ortamda itriyum ile stabilize zirkonya (Y-TZP) ve magnezyum ile stabilize zirkonya (Mg-PSZ) abutmentlerin bükülme dirençlerini değerlendirdikleri çalışmalarında, Y-TZP abutmentlerin daha yüksek bükülme direnci gösterdiğini bildirmişlerdir. 
Yapılan çalışmalar, estetik bölgede yaklaşık 206 N yük ve maksimum 290 N çiğneme kuvveti bildirmektedir. ${ }^{23,24}$ Başarılı bir restorasyon için abutmentlerin bu kuvvetlerden daha yüksek değerlere dayanması, ve en az 5 yıllık klinik fonksiyon görmeleri beklenir. ${ }^{10,25}$ İn vitro araştırmalar farklı implant sistemlerine ait zirkonya abutmentlerin yeterli yük karşılama kapasitesine sahip olduğunu göstermektedir. ${ }^{25,26}$ Klinik araştırmalar da zirkonya abutmentlerin kırılma risklerinin düşük olduğunu belirtmektedir. ${ }^{27,28}$ Anterior ve premolar diş bölgelerinde kullanılan zirkonya abutmentlerin 4 yıllık takipleri sonucunda kırık rapor edilmemiştir. ${ }^{16,29}$

Yıldırım ve ark. ${ }^{17}$ in vitro bir çalışmada, bu restorasyonların kırıma dayanıklılıklarını araştırmışlardır. Alumina ve zirkonya abutmentler üzerine hazırlanmış, Empress kronlar, Branemark (Nobel Biocare, Goteborg, İsveç) implantlar üzerine uygulanmıştır. Alumina abutmentlerde 280,1 N, zirkonya abutmentlerde $737,6 \mathrm{~N}$ ortalama kırılma dayanıklıı̆ı bildirmişlerdir. Zirkonya abutment grubunun kırılma dayanıklıığı, alumina abutment grubundan iki kat daha fazla ölçülmüştür. Alumina abutmentler daha düşük kırılma dayanıkılığı göstermiştir.

Ancak alumina abutmentleri kullanan klinik çalışmalar ${ }^{27,30}$ tedavi konseptleri ve komponentlere dikkat edildiğinde mükemmel estetik sonuçlar ve yüksek başarı oranları bildirmiştir. Andersson ve ark. ${ }^{31}$ tek diş alümina abutmentlerde \%93-100 başarı bildirmişlerdir.

Foong ve ark. $^{32}$ in vitro bir çalışmada, titanyum ve zirkonya abutmentlerin kırıma dayanıklılıklarını karşılaştırmışlardır. Çalışmalarında 22 adet implant destekli anterior tek kron restorasyonları, rastgele eşit ayırarak titanyum abutment (grup t) ve zirkonya abutment (grup z) olmak üzere 2 farklı test grubu oluşturmuşlardır. Abutmentler, akrilik rezin içerisine yerleştirilmiş implantlar üzerine bağlanmış ve CAD/CAM (Etkon system) sistemiyle üretilmiş kronlar ile restore edilmiştir. Yükleme protokolü başarısız olana dek, çiğneme fonksiyonları periyodik olarak stimule edilmiştir. Başarısız örnekler, SEM ve fraktografi ile analiz edilmiştir. $30^{\circ}$ açıyla yerleştirilmiş olan abutmentlerden, grup t ye ortalama 81.935 defa çiğneme kuvveti uygulanmış ve ortalama maksimum kırılma dayanıkıı̆̆ı 270 N olarak ölçülmüştür. Grup z ye ise, ortalama 26.296 defa çiğneme kuvveti uygulanmış ve ortalama maximum kırılma dayanıklıığı 140 N olarak ölçülmüştür. İki grup arasındaki fark istatistiksel olarak anlamlı bulunmuştur. Zirkonya abutmentlerde kırık lokalizasyonu abutment üzerinde belirtilirken, titanyum abutmentlerde ise abutment vida kırığı olarak belirtilmiştir. Titanyum abutmentlerde, abutment vidası ve implant üzerinde deformasyon belirtilmiştir.

Att ve ark. ${ }^{33}$ in vitro bir çalışmada, implant destekli farklı tam seramik restorasyonların kırılma dayanıklılıklarını çiğneme simulasyonu ve statik yükleme sonrası değerlendirmiştir. Internal bağlantıya sahip 96 implant (Replace, Nobel Biocare, Goteborg, İsveç) 3 gruba ayrılmıştır. Kontrol grubundaki implantlara titanyum abutmentler, test gruplarına ise Procera alumina ve Procera zirkonya abutmentler (Nobel Biocare, Goteborg, İsveç) uygulamışlardır. Üst yapı olarak Procera alumina ve Procera zirkonya tam seramik kronlar hazırlanmıştır. Çiğneme simulatöründe 5 yıllık kullanım süresini taklit etmek için 1,2 milyon siklus uygulanmıştır.

En yüksek kırılma dayanıklılığı, titanyum abutment/alumina kron (1454 N) kombinasyonunda elde edilmiş, en düşük dayanıklılık, alumina abutment/ zirkonya kron (241 N) kombinasyonunda ölçülmüştür. Zirkonya abutment/zirkonya kron için $457 \mathrm{~N}$ olarak ölçülmüştür. Bütün abutment-kron kombinasyonlarının anterior bölgede oluşan çiğneme kuvvetlerine karşı dayanıklı olduğu sonucuna varmışlardır. Çalışmada elde edilen değerlerin diğer çalışmalardan düşük olmasının nedenini ise yaşlandırma işleminden kaynaklanabileceğini belirtmişlerdir.

Abutment materyallerinin kalınlığı ve açılanması kırılma dirençlerine etki edebilmektedir. Albosefi ve ark. $^{34}$ farklı kalınlık ve açılardaki bireysel zirkonya abutmentlerin kırılma direncini karşılaştırdıkları çalışmada, 40 adet bireysel zirkonya abutmenti 4 gruba ayırmış, $A 1$ ve $B 1$ grubunda sırasıyla $0,7 \mathrm{~mm}$ ve $1 \mathrm{~mm}$ kalınlıkta düz implant abutmentler ;A2 ve B2 grubunda sırasıyla $0,7 \mathrm{~mm}$ ve $1 \mathrm{~mm}$ kalınlıkta $15^{0}$ açılı implant abutmentler kullanılmıştır. 0,7 mm ve $1 \mathrm{~mm}$ kalınlıktaki gruplarda, kırıma direncinde istatistiksel olarak anlamlı bir fark bulunmamış ancak açılı bireysel zirkonya abutmentler daha düşük kırılma direnci göstermiştir.

Bidra ve Rungruanganunt ${ }^{19}$ sistematik bir derlemede, 1970 - 2012 yılları arasındaki anterior bölgede kullanılan abutmentleri içeren 27 çalışmayı analiz etmişler ve 951 abutment içerisinde \%1,15 (8 alumina abutment ve 3 zirkonya abutment) kırık rapor

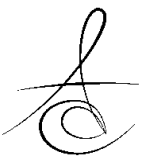


etmişlerdir. Titanyum ve döküm metal abutmentlerde kırık rapor edilmemiştir.

\section{SERAMİK ABUTMENTLERİN BİYOLOJİK YÖNDEN DEĞERLENDİRİLMESİ}

Abutment materyalinin mekanik direnci ve estetik özellikleri yanında, implant çevresindeki kemiğin stabilitesini ve yumuşak dokuların sağlı̆ını etkileyen biyolojik özellikleri de büyük önem taşımaktadır. ${ }^{35}$ Abutment materyalinin tipi, mukoza ve abutment yüzeyi arasında oluşan ataçmanı etkilemektedir. ${ }^{36,37}$ Materyalin özelliğine bağlı olarak oluşan plak akümülasyonu ve bakteri adezyonu soncunda görülebilen periodontal dokulardaki enflamasyon ve sonrasında gelişebilen kemik kaybı, implant çevresindeki dokuların sağlığını tehdit eden faktörlerdir. 4,35

Anterior bölgedeki abutmentlerin biyolojik sonuçlarının değerlendirildiği sistematik bir derlemede $^{19} 27$ çalışmanın 6'sında bukkal fistül rapor edilmiştir. Vida tutuculu restorasyonlarda, sadece external hex implantlarda görülmesinin olası nedeni, abutment-implant arasındaki aralı̆a yumuşak dokunun yürümesi olarak belirtilmiştir. Siman tutuculu restorasyonlarda ise temizlenemeyen siman artıklarından olabileceği belirtilmiştir. Sistematik derleme sonucu 6 çalışmada belirtilen diğer bir biyolojik komplikasyon ise, prefabrike titanyum abutmentlerde daha fazla görülen dişeti çekilmesidir. Prefabrike titanyum abutmentlerde daha fazla görülmesinin nedeninin tesadüfi olabileceği ya da muhtemelen prefabrike abutmentlerin bireysel abutmentlere göre gingival dokuya daha az destek sağlaması, titanyum abutmentler uzun süredir kullanıldıkları için, daha çok çalışmada rapor edilmeleri, titanyum abutmentlerde, seramik abutmentlere göre dişeti çekilmesinin daha kolay görülebilmesi ve kaydedilmesiyle ilişkilendirmişlerdir.

Abutment materyallerinin, abutment ve implantlar çevresindeki yumuşak dokulara etkisinin değerlendirildiği histolojik çalışmalarda, zirkonya ve titanyum materyali çevresindeki dokuların benzer özellikler gösterdiği belirtilmiştir. ${ }^{36-38}$

Welander ve ark. $^{39}$ yaptıkları çalışmada titanyum, zirkonya ve altın-platin alaşımından yapılmış abutmentleri köpeklerde karşılaştırmışlar ve titanyum ile zirkonya etrafında şekillenen yumuşak doku bariyerinin eşit ve stabil olduğunu tespit etmişlerdir. Ancak, altın-platin abutment çevresindeki bariyer epitelinin 2-5 aylık iyileşme periyodu süresince apikale doğru kaydığı ve marjinal kemik seviyesinin azaldığı saptanmıştır. Bununla birlikte diğer abutmentlere kıyasla altın-platin abutmentlerde bağ dokusunda daha az miktarda kollajen ve fibroblastların olduğu belirlenmiştir.

Degidi ve ark. ${ }^{40}$ titanyum ve zirkonya iyileşme başlıkları çevresindeki dokuları 6 aylık iyileşme periyodu sonrasında değerlendirmişlerdir. Araştırmacılar plak akümülasyonu ve sondalamada kanama değerleri açısından abutmentler arasında bir fark bulamazken, histolojik incelemeler enflamatuar infiltrasyonun daha çok titanyum başılılar çevresinde olduğunu ortaya koymuştur .

Farklı abutment materyallerinin; yüzey pürüzlülükleri, serbest yüzey enerjileri ve implant-abutment bağlantıları implant çevresi dokuların sağlığına etki edebilmektedir. ${ }^{41}$ Abutment materyali, epitelyal örtücülüğü sağlayabilmeli ve plak akümülasyonunu önleyecek şekilde pürüzsüz olmalıdır. ${ }^{42}$ Abutment yüzeyinde plak akümülasyonuna neden olan bir diğer faktör ise ıslanabilirlik olarak da tanımlanan yüzey serbest enerjisidir. ${ }^{43}$ Yüksek yüzey serbest enerjisinin implant ve abutment yüzeyinde biyofilm formasyonunu stimüle ettiği ve bakteri kolonizasyonunu arttırdığı gösterilmiştir. Ancak bakteri tutunmasında, yüzey pürüzlüğünün yüzey serbest enerjisine göre daha etkili olduğu gözlenmiş̧ ${ }^{41,44}$ hem yüzey pürüzlüğünün hem de yüzey serbest enerjisinin yüksek olması durumunda biyofilm formasyonunun arttığı tespit edilmiştir. ${ }^{43}$ Salihoğlu ve ark. ${ }^{45}$ titanyum ve zirkonya abutmentlerin yüzey serbest enerjilerini ölçtükleri çalışmada, zirkonyanın daha düşük yüzey serbest enerjisine sahip olduğunu tespit etmişlerdir.

Farklı abutment materyallerinin plak ve bakteri akümülasyonu açısından karşılaştıııldıkları çalışmaların bulguları farkllık göstermektedir. Salihoğlu ve ark. ${ }^{45}$ titanyum ve zirkonya abutmentler ağıza yerleştirildikten 5 hafta sonra çevresindeki cep derinliklerini ölçmüşler ve gingival biyopsi almışlardır. Cep derinliği ve bakteri kolonizasyonu bakımından titanyum ve zirkonya abutmentler arasında istatistiksel olarak anlamlı bir fark bulamamışlardır. Rimodini ve ark. ${ }^{46}$ zirkonya ve titanyum abutmentleri in vivo ve in vitro ortamlarda karşılaştırmış, in vitro olarak iki abutment materyali arasında bakteri tutunması açısından fark bulunamazken, in vivo koşullarda zirkonya yüzeyine daha az bakteri akümülasyonu olduğu belirtilmiştir.

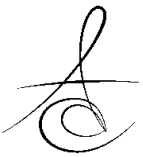


Atatürk Üniv. Diş Hek. Fak. Derg.

J Dent Fac Atatürk Uni

Supplement: 10, YIl: 2015, Sayfa : 148-156
GÜNAL, ULUSOY, DURMA YÜKSEL KURTULMUŞ- YILMAZ
Titanyum ve zirkonya materyalinin karşılaştırıldığı bir başka çalışmada, ${ }^{47} 24$ saat boyunca ağız ortamında tutulan titanyum ve zirkonya disklerin yüzeylerindeki bakteri miktarı karşılaştırılmış, zirkonya yüzeyinde daha az bakteri olduğu tespit edilmiştir.

Sailer ve ark. seramik ve metal abutmentler üzerine yaptıkları sistematik derlemede, ${ }^{6}$ beş yıllık takip sonunda seramik abutmentler çevresindeki kümülatif dişeti çekilmesi oranı \%8.9, metal abutmentler çevresindeki dişeti çekilmesi oranı \%3,8 olarak belirlenmiştir. Araştırmacılar bu ilginç sonucu, seramik abutmentlerin estetik nedenlerle daha çok anterior bölgede kullanılmasına ve bu bölgedeki dişeti kalınlığının metal abutmentlerin tercih edildiği molar bölgeye göre daha az olmasının dişeti çekilmesi oranını arttırmasına bağlamışlardır.

Rompen ve ark. ${ }^{48}$ yaptıkları çalışmada, 49 konkav titanyum abutmenti ve 5 konkav zirkonya abutmenti biyolojik açıdan değerlendirmişlerdir. 1, 3, 6, 12, 18 ve 24. aylarda dijital fotoğraf alınmış, yumuşak doku seviyesindeki değişimler ölçülmüş, estetik sonuçlar subjektif olarak değerlendirilmiştir. Araştırmacılar, $\% 87$ oranında yumuşak dokuda stabilite, \% 13 oranında $0,5 \mathrm{~mm}$ 'den fazla olmayan dişeti çekilmesi olduğunu belirtmişlerdir. Konkav transmukozal implant kompanentlerinin kullanımının, estetik bölgede yumuşak doku stabilitesine daha çok olanak sağlayabileceğini önermişlerdir. Titanyum ve zirkonya abutmentler arasında, yumuşak doku stabilitesinde fark belirtmemişlerdir.

İmplant destekli tek diş restorasyonlarda 28 konkav zirkonya abutmentler ile yapılan bir çalışma$\mathrm{da}^{49}$ hastalar ortalama 20,8 ay takip edilmiş, dijital fotoğraflar alınmıştır. Araştırmacılar, bukkal gingival dokuda minimal dişeti çekilmesi ve bağ dokusu hacminde artış olduğu sonucuna varmışlardır.

İmplant ve abutment arasında hassas bir uyum yoksa biyolojik ve biyomekanik hasar oluşmaktadır. ${ }^{50}$ Abutmente bükme momenti olan kuvvetler art arda geldiğinde, yorulma ve aşınmaya bağlı olarak marjinal mikroaralık miktarı artmaktadır. ${ }^{51}$ Bunun sonucunda oluşan mikrobiyal sızıntı ve plak retansiyonu enflamasyona yol açmaktadır ve bu nedenle mikroaralık kemik kaybını etkileyen faktörlerden biri olarak düşünülmektedir. Mikroaralık miktarı, implant ve abutment tasarımından, abutment materyalinden, abutmentin freze işleminin hassaslığından ve implantabutment bağlantı tipinden etkilenebilmektedir. ${ }^{52}$
Titanyum implantlar üzerine yerleştirilen titanyum, alumina ve zirkonya abutmentler arasındaki mikroaralığın değerlendirildiği bir çalışmada, ${ }^{53}$ palatinal bölgede titanyum abutmentlerde seramik abutmentlere göre daha fazla mikroaralık oluştuğu gözlenmiştir. Dört farklı zirkonya abutmentin test edildiği bir çalışmada, ${ }^{54}$ elde edilen mikroaralık değerlerinin 0,38 1,83 $\mu \mathrm{m}$ arasında değiştiği ve bu değerlerin de literatürde titanyum abutmentler için tespit edilen mikroaralık değerlerinden daha düşük olduğu öne sürülmüştür.

\section{SERAMİK ABUTMENTLERİN ESTETİK YÖNDEN DEĞERLENDİRİLMESİ}

Estetik sonuçlar temel olarak, anterior bölgedeki implant restorasyonlarının çevresindeki yumuşak dokudaki renk değişimine dayandırılabilir. Bidra ve Rungruanganunt ${ }^{19}$ anterior bölgedeki implant abutmentleri ile ilgili sistematik derlemelerinde, klinik çalışmalarda implant çevresindeki mukozal renk değişiminin, titanyum abutmentlerle karşılaştırıldığında zirkonya abutmentlerde daha az olduğunu, fakat estetik açıdan hasta memnuniyeti bakımından önemli bir fark olmadığını belirtmişlerdir.

Andersson ve ark. ${ }^{31}$ randomize kontrollü klinik çalışmalarında, anterior bölgedeki titanyum (kontrol grubu) ve alumina (test grubu) abutmentleri estetik açıdan karşılaştırmışlardır. Alumina abutmentlerin restorasyonunda, tam seramikler ve tek parça vidalı restorasyonlar kullanılmıştır. Titanyum abutmentlerin üst yapısında ise tam seramik kronlar ve metalseramik kronlar kullanılmıştır. Hastaların bir yıl takibi sonucunda, bütün hastalar estetik sonuçtan memnun olmuş ve implant çevresi yumuşak dokularda renk değişiminden bahsetmemişlerdir.

Jung ve ark. $^{55}$ metal abutment (titanyum ve döküm altın alaşımı) ve alumina abutmentler çevresindeki mukozadaki renk değişimini, spektrofotometre kullanarak değerlendirmişlerdir. Alumina abutmentlerin restorasyonunda alumina seramikler, metal abutmentlerin üst yapısında metal-seramik restorasyonlar kullanılmıştır. Araştırmacılar alumina abutmentlerin çevresindeki renk değişiminin, metal abutmentlere göre daha az olduğunu belirtmişlerdir.

Zembic ve ark. $^{3}$ CAD-CAM ile hazırlanmış zirkonya ve titanyum abutmentleri estetik açıdan karşılaştırmışlardır. Zirkonya abutmentlerin restorasyonunda, tam seramikler ve tek parça vidalı restoras-

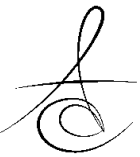


yonlar kullanılmıştır. Titanyum abutmentlerın üst yapısında metal-seramik restorasyonlar kullanılmıştır. İmplant çevresi yumuşak dokulardaki renk değişimi, spektrofotometre ile değerlendirilmiştir. Zirkonya ve titanyum abutmentlerin çevresindeki mukoza, kontrol grubundaki doğal dişlerin mukozasıyla karşılaştırıldığında renk değişikliği göstermiş, ancak zirkonya ve titanyum arasındaki implant çevresi mukozadaki renk değişikliği istatistiksel olarak anlamlı bulunmamıştır.

Galluci ve ark. ${ }^{56}$ titanyum abutmentler (kontrol grubu) ile titanyum alt yapılı zirkonya abutmentleri (test grubu) 20 hastada değerlendirmişlerdir. Kontrol grubunda metal-seramik restorasyonlar, test grubunda ise tam seramik restorasyonlar kullanılmıştır. Estetik değerlendirmede, klinisyenlerden ve hastalardan bağımsız olarak spesifik subjektif ve objektif kriterler kullanılmış ve sonuçlarda istatistiksel açıdan anlamlı bir fark bulunamamıştır.

Bressan ve ark. ${ }^{57}$ CAD-CAM titanyum abutment, döküm altın alaşım abutment ve CAD-CAM zirkonya abutmenti 20 hastada karşılaştırmışlardır. Üç tip abutment de tam seramik kronlarla restore edilmiştir. İmplant çevresindeki mukozadaki renk değişimi spektrofotometre ile değerlendirilmiştir. Üç tip abutmentde de implant çevresi mukozada, normal mukoza rengine göre değişme oduğu belirtilmiş, fakat en az renk değişimi zirkonya abutmentlerde gösterilmiştir. Zirkonya abutmentlerle döküm altın abutmentler arasındaki peri-implant mukozadaki renk değişiminde, önemli bir farklılık olmadığı belirtilmiştir. Titanyum abutmentlerdeki peri-implant mukozadaki renk değişiminde ise önemli derecede farklılık olduğu belirtilmiştir.

van Brakel ve ark. ${ }^{58} 11$ hastada anterior bölgede uygulanan 15 implant üzerine bireysel hazırlanmış titanyum ve zirkonya abutmentleri spektrofotometre ile değerlendirmişlerdir. Araştırmacılar, mukoza kalınlığının 2 mm'den fazla olduğu durumlarda, titanyum ve zirkonya abutmentler arasındaki peri-implant mukozadaki renk değişiminin subjektif olarak fark edilemeyebileceğini belirtmişlerdir.

Happe ve ark. ${ }^{59}$ kişisel zirkonya abutmentler ile restore edilmemiş komşu veya kontralateral dişteki mukozal dokuyu spektrofotometre ile ölçmüşlerdir. Zirkonya abutmentler $2 \mathrm{~mm}$ genişliğinde, açık sarı seramik materyal ile kaplanmıştır. Araştırmacılar, implant çevresi mukoza ile doğal diş çevresi arasındaki mukoza renk farklıı̆ını minimal olarak belirtmişlerdir.
Hosseni ve ark. $^{60} 3$ yıllık prospektif çalışmalarında, klinisyenler tarafından anterior bölgeye uygulanan döküm metal, titanyum ve zirkonya abutmentlerin estetik sonuçları, hem klinisyenler hem de hastalar tarafından subjektif olarak analiz edilmiştir. Klinisyenler, metal ve zirkonya abutmentler arasındaki implant çevresindeki mukozal renk değişimi arasında önemli bir farklılık belirtmemiş, zirkonya abutmentlerdeki çevre dokudaki renk değişiminin biraz daha az olduğunu rapor etmişlerdir. Hastalar, tam seramik ve metal seramik restorasyonlar arasında estetik memnuniyet açısından bir fark belirtmemişlerdir.

\section{SONUÇ}

Modern implantolojinin erken dönem uygulamalarında, temel hedef doku sağlığı ve implantın yaşam süresiyken son dönemlerde, restorasyonun başarı kriterleri arasında estetik de büyük önem kazanmıştır. Titanyum abutmentler, biyouyumluluğu, üstün mekanik özellikleri ve uzun dönem klinik çalışmalardaki başarısı ile yakın bir döneme kadar altın standart olarak kabul edilmekteydi. Ancak daha estetik bir materyal arayışı sonucu seramik abutmentler geliştirilmiş, alümina ve zirkonya tercih edilen materyaller arasına girmiştir.

Literatüre bakıldığında, araştırmaların daha çok zirkonya ve titanyum abutmentler üzerinde yoğunlaştığı görülmektedir. Titanyum abutmentler yaygın olarak kullanılmalarına rağmen, implant çevresi dokuların sağlığına etkileri ve estetik açıdan, alumina ve zirkonya abutmentlere olan üstünlüklerinden bahsedilememektedir. Son yıllarda kullanımı artan zirkonya abutmentlerin estetik, mekanik ve implant çevresi dokulardaki etkileri değerlendirildiğinde başarılı sonuçlar alınmaktadır.

İn vitro ve in vivo çalışmalar seramik abutment kullanımını tek diş implant üstü tam seramik restorasyonlarla sınırlamaktadır. Abutmentlerin, dayanıklılıklarının arttırılması posterior bölgede kullanımlarını sağlayacaktır. Zirkonya seramikler ve abutmentler ile ilgili yoğun çalışmalar yapılmaktadır ve popülerlikleri artmaktadır. Sinterleme işlemi öncesinde, zirkonyaya renklendirici oksitler ilave edilerek beyaz rengini değiştirip estetik kalitesini arttırmaya çalışılmaktadır.

Günümüze kadar yapılmış olan çalışmalarda alumina ve zirkonya abutmentlerle ilgili başarılı sonuçlar bildirilmiş olmasına rağmen, geniş hasta

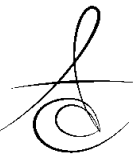


gruplarını içeren ve uzun süreli takipleri yapılmış randomize kontrollü klinik çalışmalara ihtiyaç olduğu görülmektedir.

\section{KAYNAKLAR}

1. Blatz BM, Bergler M, Holst S, Block MS. Zirconia Abutments for Single-Tooth Implants-Rationale and Clinical Guidelines. J Oral Maxillofac Surg 2009;67:74-81.

2. Gomes AL, Montero J. Zirconia implant abutments: A review. Med Oral Patol Oral Cir Bucal 2011;16:50-5.

3. Zembic A, Sailer I, Jung RE, Hammerle $\mathrm{CH}$. Randomized-controlled clinical trial of customized zirconia and titanium implant abutments for singletooth implants in canine and posterior regions: 3year results. Clin Oral Implants Res 2009;20:8028.

4. Yılmaz HG, Kurtulmuş-Yılmaz S. Farklı Abutment Materyallerinin İmplant Çevresi Dokuların Sağlığına Etkileri. Ege Üniv Diş Hek Fak Derg 2011;32:69-75.

5. Jung RE, Sailer I, Hämmerle $\mathrm{CH}$, Attin $\mathrm{T}$, Schmidlin $P$. In vitro color changes of soft tissues caused by restorative materials. Int J Periodontics Restorative Dent 2007;27:251-7.

6. Sailer I, Philipp A, Zembic A, Pjetursson BE, Hämmerle $\mathrm{CH}$, Zwahlen $\mathrm{M}$. A systematic review of the performance of ceramic and metal implant abutments supporting fixed implant reconstructions. Clin Oral Implants Res 2009;20:4-31.

7. Prespino $V$, Ingber $A$. Esthetic high-strength implant abutments. Part I. J Esthet Dent 1993; 5:29-36.

8. Prespino V, Ingber A. Esthetic high-strength implant abutments. Part II. J Esthet Dent 1993;5: 63-8.

9. Kohal RJ, Att W, Bachle M, Butz F. Ceramic abutments and Ceramic oral implants. An update. Periodontol 2000 2008;47:224-30.

10. Vanlıoğlu B, Özkan Y, Özkan Y. Estetik Bölgede İmplant-üstü Restorasyonlarda Güçlendirilmiş Seramik Dayanaklar. Atatürk Üniv Diş Hek Fak Derg 2012; 5:58-64.

11. Andersson $B$, Schaerer $P$, Simion $M$, Bergstrom $C$. Ceramic implant abutments used for short-span fixed partial dentures: a prospective 2-year multicenter study. Int J Prosthodont 1999;12:31824.
12. Eğilmez F, Biçer A, Ergün G. Zirkonyumla Güçlendirilmiş Seramikler ve Dental İmplantolojide Kullanımı. Cumhuriyet Üniv Diş Hek Fak Derg 2010;13:72-80.

13. Sadeq A, Cai Z, Woody RD, Miller AW. Effect of interfacial variables on ceramic adherence to cast and machined commercially pure titanium, ] Prosthet Dent 2003;8:255-62.

14. Firidinoğlu K, Toksavul S, Toma M. İmplat destekli sabit protezlerde seramik abutment kullanımı. Ege Üniv Diş Hek Fak Derg 2007;28:145-50.

15. Aboushelib NM, Salameh Z. Zirconia Implant Abutment Fracture: Clinical Case Reports and Precautions for Use. Int J Prosthodont 2009;22:616-9.

16. Glauser R, Sailer I, Wohlwend A, Studer S, Schibli $M$, Scharer $P$. Experimental zirconia abutments for implant-supported single-tooth restorations in esthetically demanding regions: 4-year results of a prospective clinical study. Int J Prosthodont 2004;17:285-90.

17. Yıldırım M, Fischer $H$, Marx R, Edelhoff D. In Vivo Fracture Resistance of Implant-Supported AllCeramic Restorations. J Prosthet Dent 2003;90:325-30.

18. Yıldırım M, Edelhoff D, Hanisch O, Speikermann H. Ceramic Abutments A New Era in Achieving Optimal Esthetics in Implant Dentistry. Int J Periodontics Restorative Dent 2001;20:81-9.

19. Bidra A, Rungruanganunt P. Clinical outcomes of implant abutments in the anterior region: a systematic review. J Esthet Restor Dent 2013;25:159-76.

20. Piconi C, Maccauro G. Zirconia as a ceramic biomaterial. Biomaterials 1999;20:1-25.

21. Guess PC, Att W, Strub JR. Zirconia in fixed implant prosthodontics. Clin Implant Dent Relat Res. 2012;14:633-45.

22. Sundh A, Sjögren G. A study of the bending resistance of implant-supported reinforced alümina and machined zirconia abutments and copies. Dent Mater 2008;24:611-7.

23. Kiliaridis $S$, Kjellberg $H$, Wenneberg B, Engstrom $C$. The relationship between maximal bite force, bite force endurance, and facial morphology during growth. A cross-sectional study. Acta Odontol Scand 1993;51:323-31.

24. Haraldson T, Carlsson GE, Ingervall B. Functional

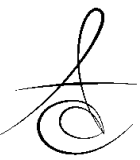


state, bite force and postural muscle activity in patients with osseointegrated oral implant bridges. Acta Odontol Scand 1979;37: 195-206.

25. Butz F, Heydecke G, Okutan M, Strub JR. Survival rate, fracture strength and failure mode of ceramic implant abutments after chewing simulation. J Oral Rehabil 2005;32:838-43.

26. Gehrke P, Dhom G, Brunner J, Wolf D, Degidi M, Piattelli A. Zirconium implant abutments:fracture strength and influence of cyclic loading on retaining-screw loosening. Quintessence Int 2006;37:19-26.

27. Henriksson K, Jemt T. Evaluation of custom-made procera ceramic abutments for single-implant tooth replacement: a prospective 1-year follow-up study. Int J Prosthodont 2003;16: 626-30.

28. Nothdurft F, Pospiech P. Prefabricated zirconium dioxide implant abutments for single-tooth replacement in the posterior region: evaluation of peri-implant tissues and superstructures after 12 months of function. Clin Oral Implants Res 2010;21:857-65.

29. Canullo L. Clinical outcome study of customized zirconia abutments for single-implant restorations. Int J Prosthodont 2007;20:489-93.

30. Hegenbarth EA. Esthetic and prosthetic considerations of Procera development on implants and teeth-a technical analysis. Appl Osseointegration Res 2004;4:22-6.

31. Andersson B, Taylor A, Lang BR, Scheller $H$, Scharer $P$, Sorensen JA, Tarnow D. Alumina ceramic implant abutments used for single-tooth replacement: a prospective 1 to 3 year multicenter study. Int J Prosthodont 2001;14:432-8.

32. Foong JK, Judge RB, Palamara JE, Swain MV. Fracture resistance of titanium and zirconia abutments: an in vitro study. J Prosthet Dent 2013:109;304-12.

33. Att W, Kurun S, Gerds T, Strub JR. Fracture resistance of single-tooth implant-supported allceramic restorations after exposure to the artificial mouth. J Oral Rehabil 2006;33:380-6.

34. Albosefi A, Finkelman M, Zandparsa R. An In Vitro Comparison of Fracture Load of Zirconia Custom Abutments with Internal Connection and Different Angulations and Thickness: Part I. J Prosthodont 2014;doi:10.1111/jopr.12118.
35. Pjetursson BE, Bragger U, Lang NP, Zwahlen M. Comparison of survival and complication rates of tooth-supported fixed dental prostheses (FDPs) and implant-supported FDPs and single crowns (SCs). Clin Oral Implants Res 2007;18:97-113.

36. Abrahamsson I, Berglundh T, Glantz PO, Lindhe J. The mucosal attachment at different abutments. An experimental study in dogs. J Clin Periodontol 1998;25:721-7.

37. Tete S, Mastrangelo F, Bianchi A, Zizzari V, Scarano A. Collagen fiber orientation around machined titanium and zirconia dental implant necks: an animal study. Int J Oral Maxillofac Implants 2009;24:52-8.

38.Barwacz CA, Brogden KA, Stanford CM, Dawson DV, Recker EN, Blanchette D. Comparison of proinflammatory cytokines and bone metabolim $\mathrm{m}$ ediators around titanium and zirconia dental implant abutments following a minimum of 6 months of clinical function. Clin Oral İmplants Res 2014; doi: 10.1111/clr.12326.

39. Welander M, Abrahamsson I, Berglundh T. The mucosal barrier at implant abutments of different materials. Clin Oral Implants Res 2008;19:635-41.

40. Degidi M, Artese L, Scarano A, Perrotti V, Gehrke $P$, Piattelli A. Inflammatory infiltrate, microvessel density, nitric oxide synthase expression, vascular endothelial growth factor expression, and proliferative activity in peri-implant soft tissues around titanium and zirconium oxide healing caps. J Periodontol 2006;77:73-80.

41. Bollen CM, Papaioanno W, Van Eldere J, Schepers E, Quirynen M, van Steenberghe D. The influence of abutment surface roughness on plaque accumulation and peri-implant mucositis. Clin Oral Implants Res 1996;7:201-11.

42. Quirynen M, Papaioannou W, van Steenberghe D. Intraoral transmission and the colonization of oral hard surfaces. J Periodontol 1996;67:986-93.

43. Teughels W, Van Assche N, Sliepen I, Quirynen M. Effect of material characteristics and/or surface topography on biofilm development. Clin Oral Implants Res 2006;17:68-81.

44. Bürgers R, Gerlach T, Hahnel S, Schwarz F, Handel $G$, Gosau M. In vivo and in vitro biofilm formation

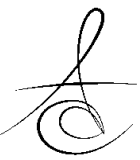


on two different titanium implant surfaces. Clin Oral Implants Res 2010;21:156-64.

45. Salihoglu U, Boynuegri D, Engin D, Duman AN, Gokalp P, Balos K. Bacterial adhesion and colonization differences between zirconium oxide and titanium alloys: an in vivo human study. Int J Oral Maxillofac Implants 2011;26:101-7.

46. Rimondini L, Cerroni L, Carrassi A, Torricelli P. Bacterial colonization of zirconia ceramic surfaces: an in vitro and in vivo study. Int J Oral Maxillofac Implants 2002;17:793-98.

47. Scarano A, Piatelli M, Caputi S, Favero GA, Patelli A. Bacterial adhesion on commercially pure titanium and zirconium oxide disks: an in vivo human study. J Periodontol 2004;75:292-6.

48. Rompen E, Raepsaet N, Domken O, Touati B, Van Dooren E. Soft tissue stability at the facial aspect of gingivally converging abutments in the esthetic zone: a pilot clinical study. J Prosthet Dent 2007; 97:119-25.

49. Redemagni M, Cremonesi S, Garlini G, Maiorana C. Soft tissue stability with immediate implants and concave abutments. Eur J Esthet Dent 2009;4:328-37.

50. Broggini N, McManus LM, Hermann JS, Medina R, Schenk RK, Buser D, Cochran DL. Peri-implant inflammation defined by the implant-abutment interface. J Dent Res 2006;85:473-8.

51. Jansen VK, Conrads G, Richter E. Microbial leakage and marginal fit of the implant-abutment interface. Int J Oral Maxillofac Implants1997;12:527-40.

52. Lindhe J, Berglundh T, Ericsson I, Liljenberg B, Marinello C. Experimental breakdown of periimplant and periodontal tissues. A study in the beagle dog. Clin Oral Implants Res 1992;3:9-16.

53. Yüzügüllü $B, A v c l ~ M$. The implant-abutment interface of alumina and zirconia abutments. Clin Implant Dent Relat Res 2008;10:113-21.

54. Baixe S, Fauxpoint G, Arntz Y, Etienne O. Microgap between zirconia abutments and titanium implants. Int J Oral Maxillofac Implants 2010;25:455-60.

55. Jung RE, Holderegger C, Sailer I, Khraisat A, Suter A, Hammerle $\mathrm{CH}$. The effect of all-ceramic and porcelain-fused-to-metal restorations on marginal peri-implant soft tissue color: a randomized controlled clinical trial. Int J Periodontics Restorative Dent 2008;28:357-65.
56. Gallucci GO, Grütter L, Nedir R, Bischof M, Belser UC. Esthetic outcomes with porcelain-fused-toceramic and all-ceramic single-implant crowns: a randomized clinical trial. Clin Oral Implants Res 2011;22:62-9.

57. Bressan E, Paniz G, Lops D, Corazza B, Romeo E, Favero $G$. Influence of abutment material on the gingival color of implant-supported all-ceramic restorations: a prospective multicenter study. Clin Oral Implants Res 2011;22:631-7.

58. van Brakel R, Noordmans HJ, Frenken J, de Roode $R$, de Wit GC, Cune MS. The effect of zirconia and titanium implant abutments on light reflection of the supporting soft tissues. Clin Oral Implants Res 2011;22:1172-78.

59. Happe A, Schulte-Mattler V, Fickl S, Naumann M, Zöller JE, Rothamel D. Spectrophotometric assessment of peri-implant mucosa after restoration with zirconia abutments veneered with fluorescent ceramic: a controlled, retrospective clinical study. Clin Oral Implants Res 2013; 100:2833.

60. Hosseini M, Worsaae N, Schiodt M, Gotfredsen KA. 3-year prospective study of implant-supported single-tooth restorations of all-ceramic and metalceramic materials in patients with tooth agenesis. Clin Oral Implants Res 2013;24:1078-87.

\author{
Yazışma Adresi: \\ Burcu Günal \\ Yakın Doğu Üniversitesi \\ Diş Hekimliği Fakültesi \\ Protetik Diş Tedavisi AD \\ Lefkoşa, Mersin10, Türkiye \\ Tel: 0392 6802030/2647 \\ Faks: 03926802025 \\ e-mail: burcugunal@hotmail.com
}

